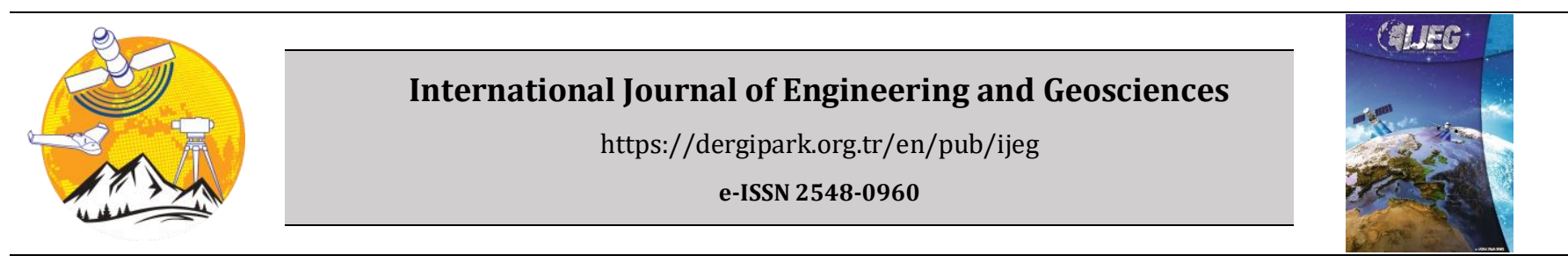

\title{
Comparative analysis of the performance of Multi-GNSS RTK: A case study in Turkey
}

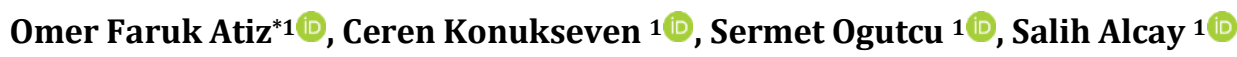 \\ ${ }^{1}$ Necmettin Erbakan University, Engineering and Architecture Faculty, Geomatics Engineering Department, Turkey
}

Keywords
CORS
GAMIT/GLOBK
Multi-GNSS
RTK
ZTD

\section{INTRODUCTION}

In recent years, Global Navigation Satellite Systems (GNSS) have been used by relative or absolute methods for millimeter to centimeter level positioning. One of the relative methods, Real Time Kinematic (RTK) method which eliminates many errors by double differencing (DD) technique is extensively used in many geospatial studies (Odijk et al. 2012; Yu et al. 2016; El-Mowafy and Kubo 2017; Erenoglu 2017; Dabove 2019; Li et al. 2019; Ogutcu 2019). The accuracy in RTK mostly depends on the distance between reference station and rover socalled -baseline length- due to the orbital errors and the changing atmospheric conditions. Apart from the error sources, the distance limitations of radio modems' due to wave propagation were another obstacle for longer baseline lengths in RTK measurements. Thanks to the Networked Transport of RTCM via Internet Protocol (NTRIP), this issue became no longer a problem (Weber et al. 2005). In present, with the development of Continuously Operating Reference Stations (CORS), the necessity of establishing a reference station is eliminated on the user side. The main purpose of CORS networks is to provide predicted RTK corrections to users using stations around the rover. These corrections can be estimated with several approaches that differ in the calculation of rover errors i.e., VRS (Virtual Reference Station), FKP (Flate Plane Correction Parameter), MAC (Master Auxiliary Concept) (Ogutcu and Kalayci 2018). However, the performance of the system still highly depends on the nearest reference station. Since the CORS offers RTK correction via Internet (GSM) protocols, it can be used for long distance RTK using a single CORS station (Wielgosz et al. 2005; Kim and Langley 2008; Odolinski et al. 2015a; Shu et al. 2018; Baybura et al. 2019; Bramanto et al. 2019). As the baseline distance becomes longer, the correlation between the reference station and rover decreases due to troposphere-ionosphere errors.

Generally, GPS and GLONASS satellite systems are used for the majority of RTK measurements as they were the first global constellations reached the Full Operational Capability (FOC). In recent years, the coverage of GNSS has been expanded with Galileo and BeiDou global satellite systems as well. With this 
development, many studies have been carried out on multi-GNSS RTK (Odolinski et al. 2015b; Li et al. 2017a; Paziewski and Wielgosz 2017; Dabove and Di Pietra 2019; Mi et al. 2019; Tian et al. 2019; Castro-Arvizu et al. 2020; Luo et al. 2020; Zhang et al. 2020). Accordingly, the additional satellites can provide a better satellite geometry and improve the positioning performance of RTK by increasing ambiguity fixing ratio.

Although many studies have been conducted referring to multi-GNSS RTK, it is still a hot topic of research. Thus, in this study, the contribution of multiGNSS to single base RTK is examined regarding different baseline distances. For this purpose, a field experiment was performed considering different satellite combinations such as GPS-only, GPS+GLONASS, and GPS+GLONASS+Galileo+BeiDou in Konya, Turkey. Also, different elevation cut-off angles $\left(10^{\circ}, 20^{\circ}, 30^{\circ}\right)$ were chosen to represent open sky and urban canyon conditions. The results were analyzed in terms of accuracy and precision. The condition of the ionosphere and troposphere were also investigated since they have a key role in the performance of real-time positioning.

\section{DATA AND METHODOLOGY}

In general, two types of positioning methods, relative and absolute, can be used for real-time precise positioning with GNSS. The Precise Point Positioning (PPP) method is one of the absolute positioning techniques which presents centimeter level positioning accuracy using precise satellite ephemeris and clock products (Zumberge et al. 1997; Kouba and Héroux 2001). Although PPP is a powerful technique, it requires a long convergence time. However, Real-Time PPP (RTPPP) method provides an accuracy of decimeter level (Alcay and Atiz 2021). On the other hand, the relative method has been used for decades and its reliability has been proven. The RTK method is based on double differencing (DD) of carrier phase measurements. For multi-GNSS integration in RTK positioning, loose and tight combined approaches can be employed (Paziewski and Wielgosz 2017). If overlapping frequencies from GNSS satellites are used to create double-differences, the tight combined approach needs to be employed. In this model, a single reference satellite is used as a pivot satellite for creating double difference observations from the all GNSS systems. As a result, "inter-system" double differencing biases, originated from the receivers, need to be established (Odijk and Teunissen 2013). Despite the tight combined model, observations from GNSS satellites with different frequencies can be integrated easily using the loose combined method. In this method, pivot satellites need to be defined separately for each GNSS system to create double-difference observations. Thus, double-differenced observations are created uniquely for each GNSS system. As a result, number of double-differenced observables decreases compared with the tight combined approach. At the same time, number of the estimated parameters also decreases due to absence of the "inter-system" double differencing biases parameter in the loose combined approach (Li et al. 2017b). In this study, loose combined model was used for multi-GNSS RTK positioning. In this way, all visible satellites at each test point were used for RTK positioning. The functional model of loose combined method can be expressed as follow:

$$
\begin{aligned}
\rho_{k l}^{m n} & =\lambda_{f_{1}} \varphi_{k l, f_{1}}^{m n}-\lambda_{f_{1}} N_{k l, f_{1}}^{m n} \\
\rho_{k l}^{m n} & =P_{k l, f_{1}}^{m n} \\
\rho_{k l}^{m n} & =\lambda_{f_{2}} \varphi_{k l, f_{2}}^{m n}-\lambda_{f_{2}} N_{k l, f_{2}}^{m n} \\
\rho_{k l}^{m n} & =P_{k l, f_{2}}^{m n}
\end{aligned}
$$

where $k$ and $l$ denote receivers, $m$ and $n$ denote GNSS satellite, $f$ land $f 2$ denote first and second frequencies, $\lambda$ is the wavelength of the associated signal, $\varphi$ denotes carrier phase data, $P$ is the pseudorange data, and $\rho$ is the geometric range. Ionospheric and tropospheric terms were neglected for simplicity. The above double-difference phase and pseudorange equations are formed separately for each GNSS system in the loose combined method. Receivers' coordinates in the geometric range and double-differenced integer phase ambiguities are the estimated parameters.

In order to investigate the contribution of multi-GNSS to single base RTK, a field experiment was conducted in Konya, Turkey between 3-6 July 2020. The NEU-CORS station, installed on the roof of the Necmettin Erbakan University Faculty of Engineering building, was used as a reference station. NEU-CORS is capable of tracking GPS, GLONASS, BeiDou and Galileo satellites with 220 channels. However, it has a GSM modem and can provide real-time data stream (Atiz et al. 2020). As rovers, three CHC i50 geodetic GNSS receivers were used. These receivers can also track GPS, GLONASS, BeiDou and Galileo satellites. In addition, rovers used in this study, have the same firmware version to avoid any systematic biases between the rovers. Simultaneous measurements have conducted using GPS-only (G), GPS+GLONASS (GR), and GPS+GLONASS+Galileo+BeiDou (GREC) satellite combinations. Four different test sites were selected for the measurements, considering the varying length of base length. The location of the sites is given in Figure 1.

A, C, and D test sites have an open sky and far from buildings which could cause multipath. In contrast, site B is closer to the highway and is a more challenging test point. The details on the baselines are provided in Table 1.

Table 1. The details of baselines

\begin{tabular}{crrrc}
\hline Name & Latitude & Longitude & Height $(\mathrm{m})$ & Distance \\
\hline Base & 37.8662 & 32.4192 & 1210.72 & - \\
Site-A & 37.9845 & 32.5902 & 1041.85 & $20.0 \mathrm{~km}$ \\
Site-B & 38.1093 & 32.7336 & 1058.94 & $38.6 \mathrm{~km}$ \\
Site-C & 38.3373 & 32.7796 & 1002.50 & $61.1 \mathrm{~km}$ \\
Site-D & 38.4861 & 32.8378 & 982.16 & $78.0 \mathrm{~km}$ \\
\hline
\end{tabular}

Traditionally in RTK method, it is assumed that rover and base stations are at similar heights. The height difference between base and rover can decrease the troposphere correlation (Edwards et al. 2010). For this case study, the height differences are between $\sim 170 \mathrm{~m}$ and $\sim 230 \mathrm{~m}$. The RTK coordinates were obtained approximately for 9 hours at each test site with G, GR, and GREC satellite configurations, in three phases. These 
three phases consist of measurements at $10^{\circ}, 20^{\circ}$ and $30^{\circ}$ elevation cut-off angles. However, for the purpose of post-process relative positioning, the first phase was extended to 5 -hours by including static data recording. The other phases were continued for 2-hours with only RTK surveying. Due to the disconnection caused by the GSM operator, the first phase could only last for 3 hours on July $4^{\text {th }}$. A special apparatus was used to place three receivers on the tripod. Hence, the rovers had the same multipath and atmospheric conditions for each test site. Figure 2 shows the instruments during the measurements. Furthermore, each rover is connected to a power supply in the box at the bottom. Thanks to these power supplies, there was no battery blackout during measurements.

As a preliminary analysis, the mean visible satellites were examined. For each session and satellite combination, the average of visible satellites is given in Table 2.
Table 2. Average of visible satellites

\begin{tabular}{lllll}
\hline Sites & Cut-off & G & GR & GREC \\
\hline \multirow{3}{*}{ A } & $10^{\circ}$ & 9 & 15 & 34 \\
& $20^{\circ}$ & 7 & 13 & 28 \\
& $30^{\circ}$ & 6 & 10 & 22 \\
\hline \multirow{3}{*}{ B } & $10^{\circ}$ & 8 & 15 & 40 \\
& $20^{\circ}$ & 7 & 13 & 29 \\
& $30^{\circ}$ & 7 & 10 & 24 \\
\hline \multirow{3}{*}{ C } & $10^{\circ}$ & 8 & 15 & 34 \\
& $20^{\circ}$ & 7 & 13 & 26 \\
& $30^{\circ}$ & 6 & 10 & 18 \\
\hline \multirow{3}{*}{ D } & $10^{\circ}$ & 8 & 15 & 35 \\
& $20^{\circ}$ & 7 & 13 & 28 \\
& $30^{\circ}$ & 6 & 9 & 21
\end{tabular}

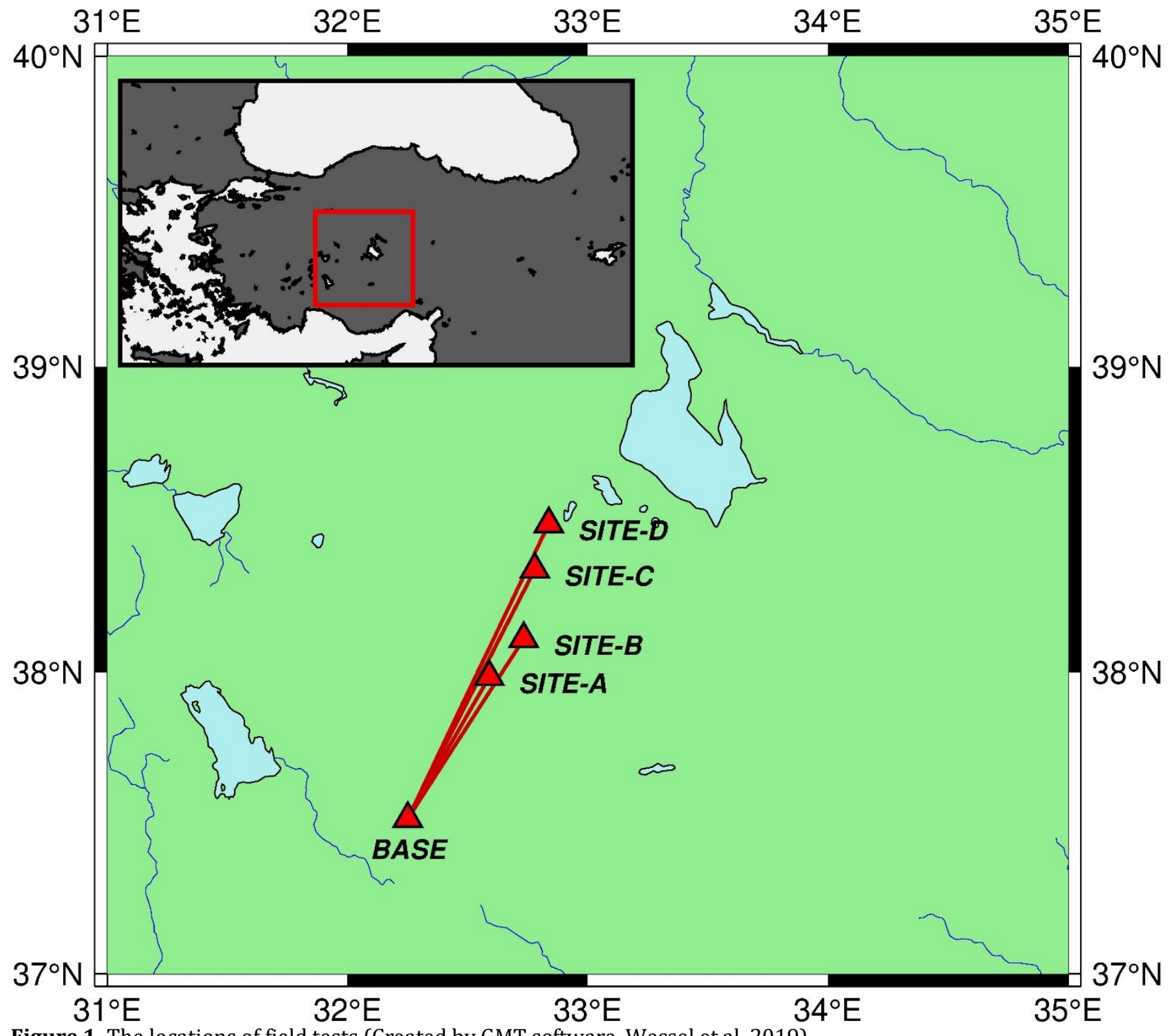

Figure 1. The locations of field tests (Created by GMT software, Wessel et al. 2019) 


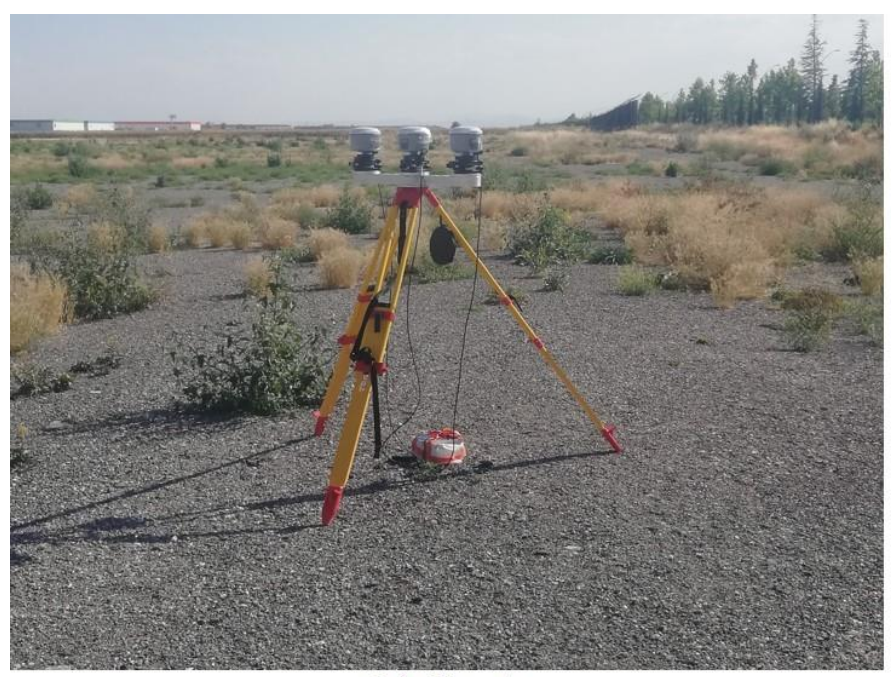

(a) Site A

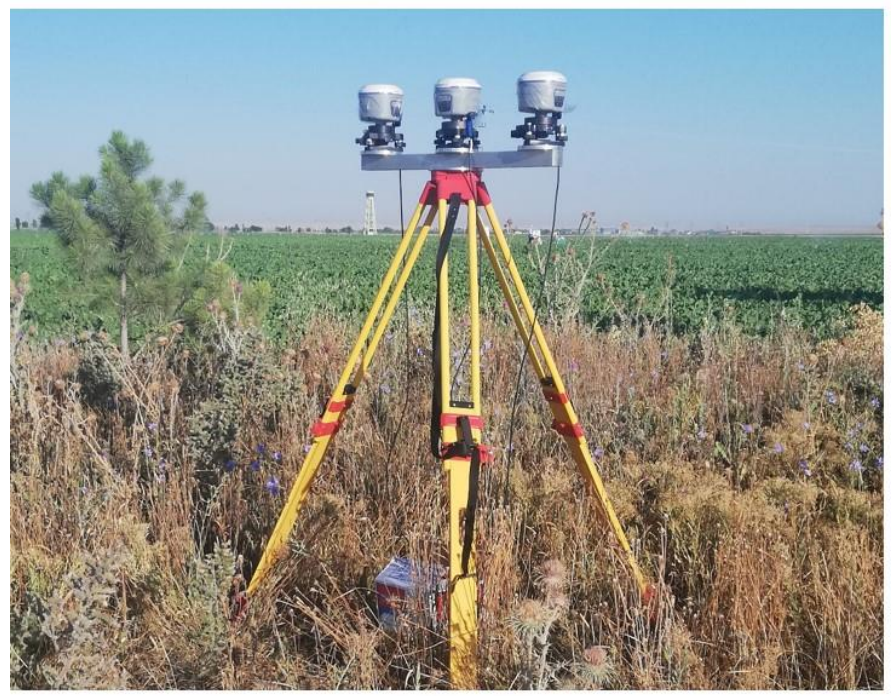

(c) Site C

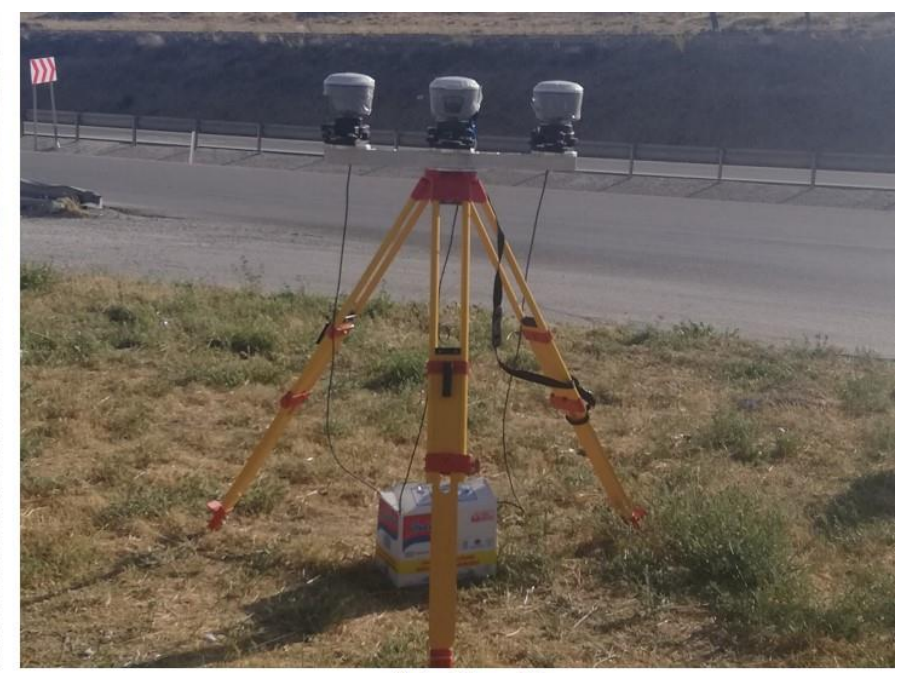

(b) Site B

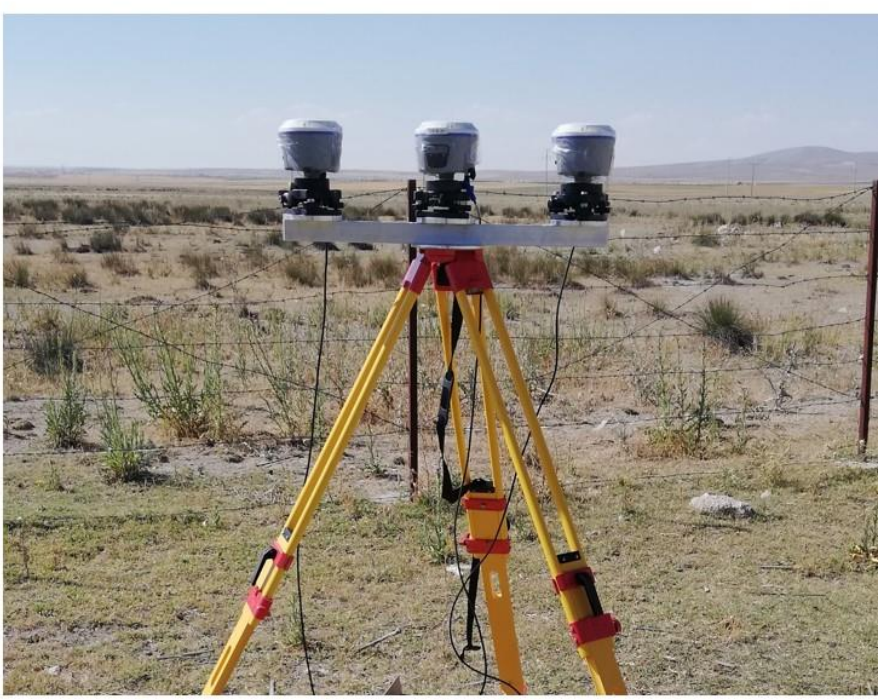

(d) Site D

Figure 2. The rovers during the measurements

A minimum of 6, 9, and 18 satellites tracked in G, GR, and GREC combinations, respectively. Due to measurements conducted at similar times of the consecutive days, the average visible satellites are close to each other in different test sites.

When utilizing different satellite combinations, the position dilution of precision (PDOP) becomes essential. PDOP values denote the state of satellite geometry. To examine this, PDOP values with respect to each cut-off angle for each session are given in Figure 3-5.

As expected for all sessions, GREC has the best PDOP while G has the worst PDOP value. All configurations are ideal at the $10^{\circ}$ cut-off angle option. Besides, a degradation occurred in the last quarter of measurements at Site-D. At the $20^{\circ}$ cut-off angle option, GREC and GR configurations are about 1.5 and 2.0, respectively. Although G has higher PDOP, it is still at a good level. PDOP change in different sites is similar as they are performed at the approximately same time of day. At the $30^{\circ}$ cut-off angle option, PDOP values are much bigger for all satellite configurations. Nevertheless, they are in a good range. 


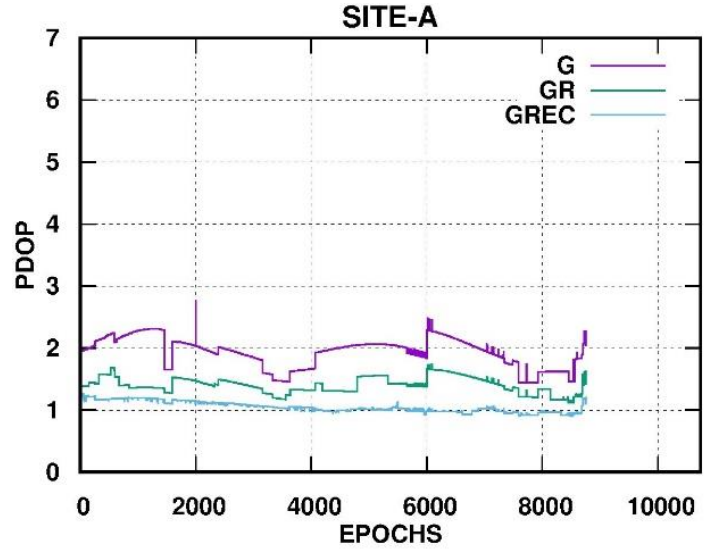

SITE-C

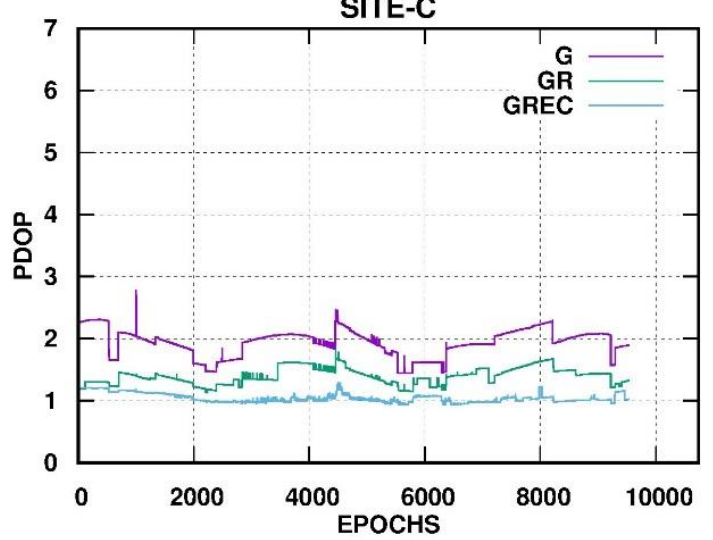

Figure 3. PDOP values for $10^{\circ}$ cut-off angle option
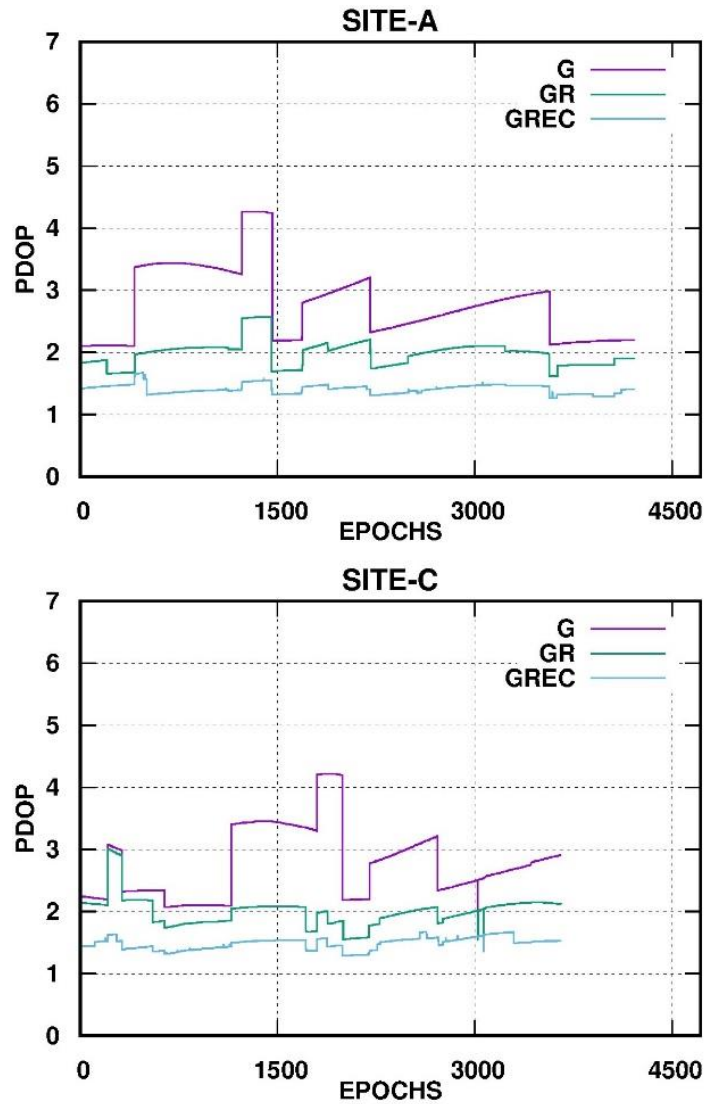

Figure 4. PDOP values for $20^{\circ}$ cut-off angle option
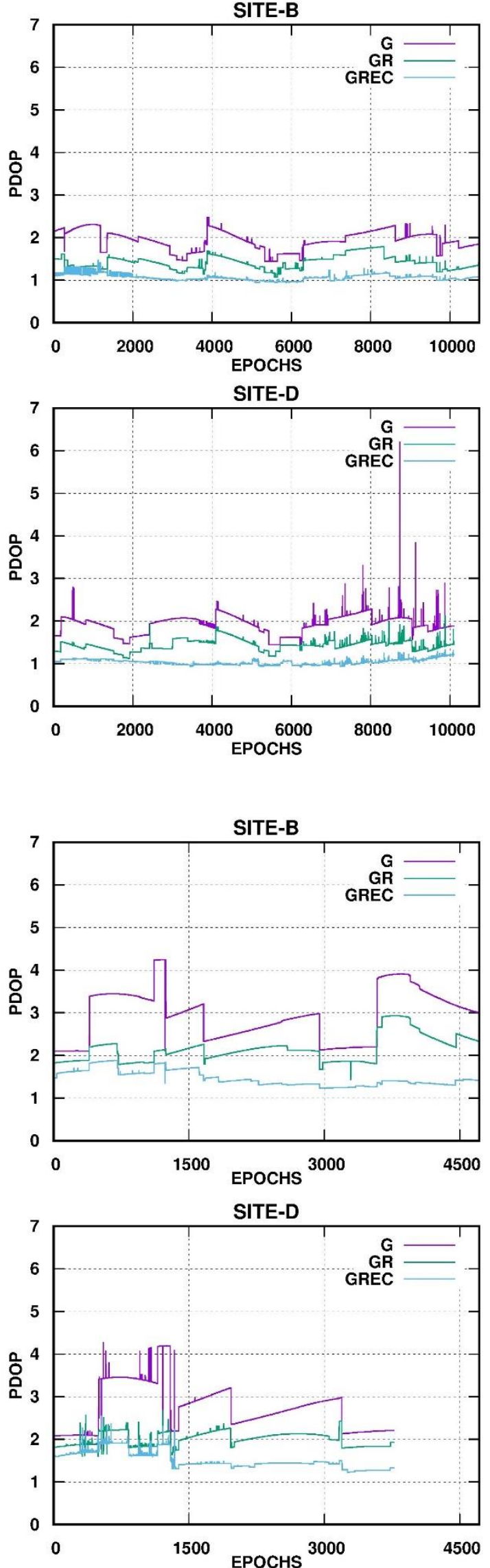


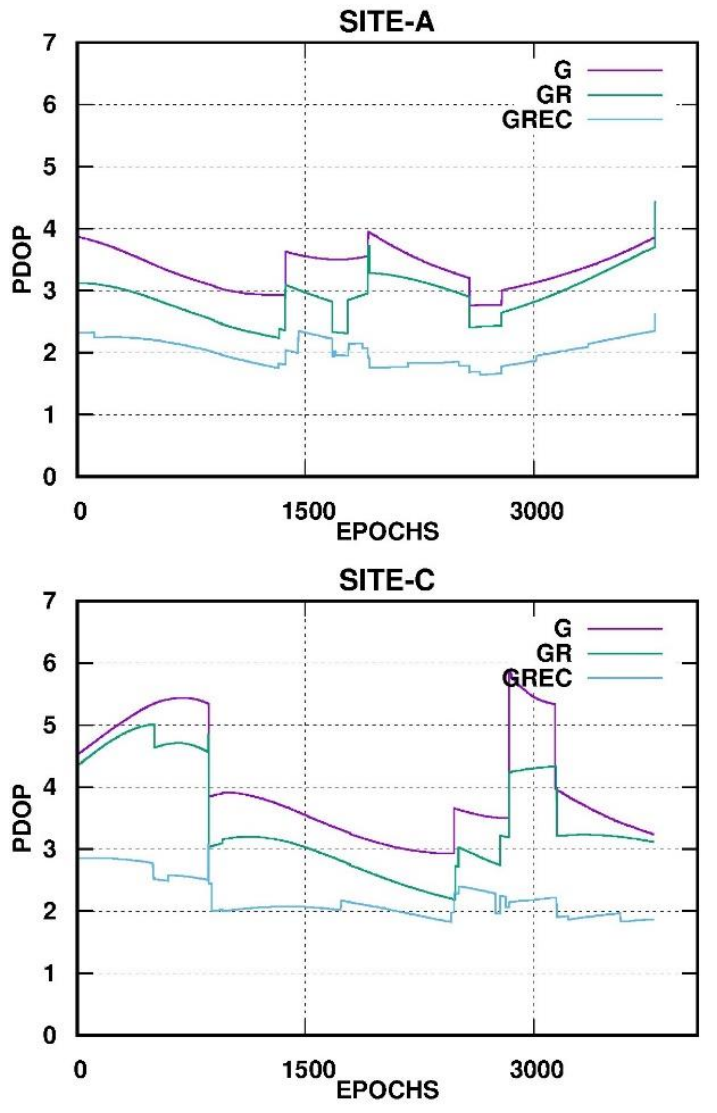

Figure 5. PDOP values for $30^{\circ}$ cut-off angle option

\section{RESULTS}

In order to make a proper accuracy analysis, the reference coordinates of each rover were obtained by post-process relative method. For this purpose, a wellknown scientific GNSS data processing software (GAMIT/GLOBK) was used (Herring et al. 2010). GAMIT/GLOBK is one of the scientific GNSS data processing software. Since the RTK measurements used in this study provide relative solutions using the NEUCORS station, the ground truth coordinates of the rovers should be obtained in the same way to avoid any systematic bias. The static data of each session was processed in GAMIT/GLOBK software. A summary of processing parameters is provided in Table 3.

The percentages of fixed Wide-Lane (WL) and Narrow-Lane (NL) phase ambiguities were checked to examine the success of post-process positioning. Fixed WL and NL phase ambiguity percentages for all three rovers were nearly identical at the same test site. For simplicity, only the mean ambiguity fixing percentages of three rovers at each test site are given in Table 4.

Using these results as ground truth, Earth Centered Earth Fixed (ECEF) RTK coordinates were converted to topocentric system (north, east, up). Since ambiguity resolution is an important issue for RTK positioning, the ambiguity-fixed solution ratio of each session was assessed (Table 5).
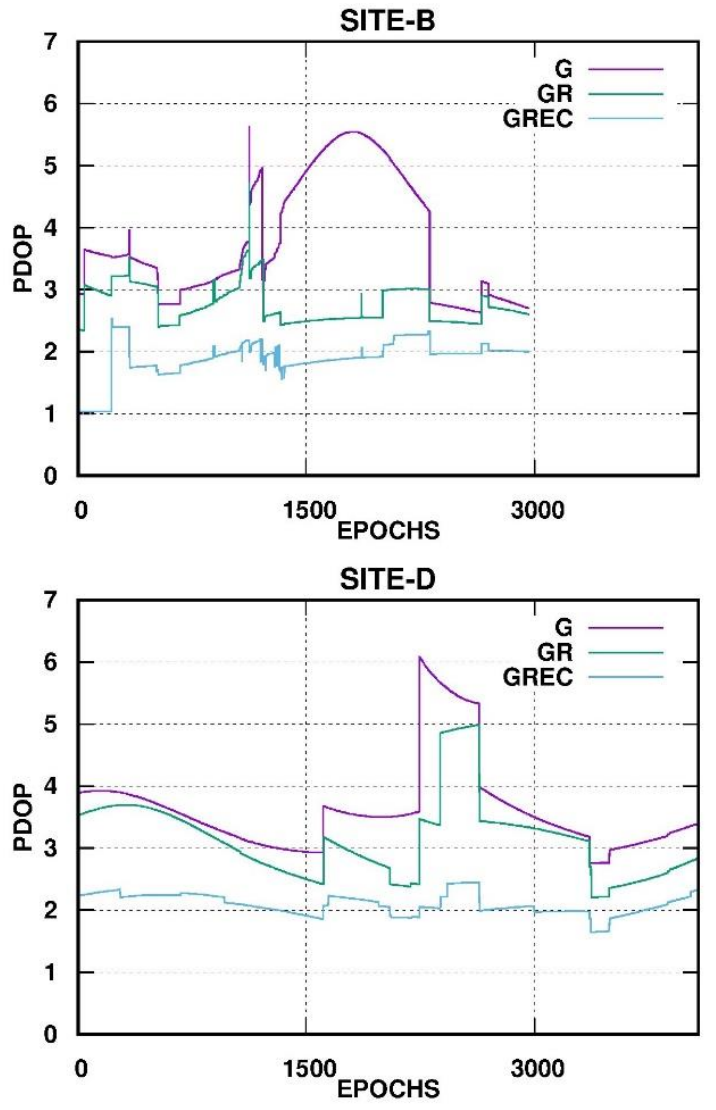

Table 3. GAMIT/GLOBK processing parameters

\begin{tabular}{ll}
\hline Parameter & Strategy \\
\hline GNSS System & GPS \\
\hline Adjustment model & Stochastic Kalman filter \\
\hline Weighting strategy & $\begin{array}{l}\text { Phase and code data } 1.0 \mathrm{~cm} / 1.0 \mathrm{~m}, \\
\text { Weighting with elevation }\end{array}$ \\
\hline Epoch interval & $30 \mathrm{~s}$ \\
\hline Elevation cut-off angle & $10^{\circ}$ \\
\hline $\begin{array}{l}\text { Satellite orbit and } \\
\text { clock }\end{array}$ & IGS final products \\
\hline Cycle-slip & Corrected \\
\hline Receiver clock jump & Corrected \\
\hline Ionosphere & $\begin{array}{l}\text { Ionosphere-free combination and } \\
\text { IGS IONEX file were used. }\end{array}$ \\
\hline A Priori troposphere & $\begin{array}{l}\text { GPT2 model (Lagler et al. 2013) } \\
\text { were applied using tropospheric } \\
\text { gradient }\end{array}$ \\
\hline $\begin{array}{l}\text { Wet tropospheric } \\
\text { delay }\end{array}$ & $\begin{array}{l}\text { Estimated as random-walk model } \\
\text { (5x10-8 m2/s) }\end{array}$ \\
\hline $\begin{array}{l}\text { Tropospheric } \\
\text { gradients }\end{array}$ & $\begin{array}{l}\text { Estimated as random-walk model } \\
\text { (5x10-8 m2/s) }\end{array}$ \\
\hline Phase ambiguity & Wide-Lane and Narrow-Lane \\
\hline Antenna phase offsets & $\begin{array}{l}\text { PCO and PCV values from up-to- } \\
\text { date IGS. atx were used. }\end{array}$ \\
\hline Satellite DCB & CODE DCB file were used. \\
\hline & \\
\hline
\end{tabular}

Table 4. WL and NL ambiguities for post-process

\begin{tabular}{ccc}
\hline Site & WL & NL \\
\hline A & $100.0 \%$ & $100.0 \%$ \\
B & $100.0 \%$ & $72.7 \%$ \\
C & $100.0 \%$ & $73.3 \%$ \\
D & $100.0 \%$ & $100.0 \%$ \\
\hline
\end{tabular}


Table 5. The percentage of ambiguity fixed solutions

\begin{tabular}{rrrrr}
\hline Sites & Cut-off & G & GR & GREC \\
\hline \multirow{3}{*}{ A } & $10^{\circ}$ & 99.9 & 100.0 & 93.3 \\
& $20^{\circ}$ & 100.0 & 100.0 & 100.0 \\
& $30^{\circ}$ & 87.5 & 100.0 & 100.0 \\
\hline \multirow{3}{*}{ B } & $10^{\circ}$ & 99.9 & 99.8 & 94.5 \\
& $20^{\circ}$ & 99.5 & 99.6 & 97.1 \\
& $30^{\circ}$ & 88.0 & 99.2 & 95.5 \\
\hline \multirow{3}{*}{ C } & $10^{\circ}$ & 100.0 & 99.7 & 98.9 \\
& $20^{\circ}$ & 100.0 & 100.0 & 96.7 \\
& $30^{\circ}$ & 99.8 & 100.0 & 92.3 \\
\hline \multirow{3}{*}{$\mathrm{D}$} & $10^{\circ}$ & 97.1 & 100.0 & 100.0 \\
& $20^{\circ}$ & 93.9 & 100.0 & 100.0 \\
& $30^{\circ}$ & 100.0 & 100.0 & 98.9 \\
\hline
\end{tabular}

According to Table 5, the minimum ambiguity fixing ratio is $87.5 \%$ in the $\mathrm{G}-30^{\circ}$ session at Site-A. Moreover, an outlier test was utilized using $10.0 \mathrm{~cm}$ threshold for north, east, and up components. Since there are not many float solutions, only ambiguity fixed results were taken into consideration. The outlier percentages for each session are given in Table 6.

As can be seen in Table 6, outlier percentages are almost similar for G, GR and GREC configurations. All results in the $\mathrm{G}-30^{\circ}$ session at Site-C are above the outlier threshold. As depicted in Table 5, 99.8\% of the ambiguities were fixed in the $\mathrm{G}-30^{\circ}$ session at Site-C. Therefore, the reason for this may be wrong fixing of the integer ambiguities obtained from RTK measurements. This session was therefore excluded from subsequent analysis. Also, an alignment was performed between three different RTK solutions at each test site to keeping the RTK solutions from three rovers share the exactly same time.

Table 6. The outlier percentages

\begin{tabular}{rrrrr}
\hline Sites & Cut-off & G (\%) & GR (\%) & GREC (\%) \\
\hline \multirow{3}{*}{ A } & $10^{\circ}$ & 0.16 & 0.05 & 0.09 \\
& $20^{\circ}$ & 5.95 & 9.17 & 4.34 \\
& $30^{\circ}$ & 0.08 & 0.11 & 0.03 \\
\hline \multirow{3}{*}{ B } & $10^{\circ}$ & 0.07 & 0.11 & 0.07 \\
& $20^{\circ}$ & 28.29 & 29.88 & 13.87 \\
& $30^{\circ}$ & 5.20 & 4.73 & 5.33 \\
\hline \multirow{3}{*}{ C } & $10^{\circ}$ & 2.40 & 0.28 & 0.23 \\
& $20^{\circ}$ & 7.95 & 5.30 & 18.86 \\
& $30^{\circ}$ & 100.0 & 8.78 & 21.38 \\
\hline \multirow{3}{*}{$\mathrm{D}$} & $10^{\circ}$ & 0.06 & 0.08 & 1.04 \\
& $20^{\circ}$ & 1.70 & 0.79 & 4.34 \\
& $30^{\circ}$ & 0.69 & 0.78 & 21.09 \\
\hline
\end{tabular}

The standard deviation (std) values are examined to evaluate repeatability. The improvement percentage can be calculated simply as given in Equation 2 .

std improvement $(\%)_{G R}=100 *\left(1-\frac{s t d_{G R}}{s t d_{G}}\right)$

where subscript $G$ and $G R$ indicate $G$ and $G R$ configurations, respectively. Besides GR, improvement for GREC can be calculated similarly. The contribution of GR and GREC configurations to the repeatability for each cut-off angle option is shown in Figure 6-8.
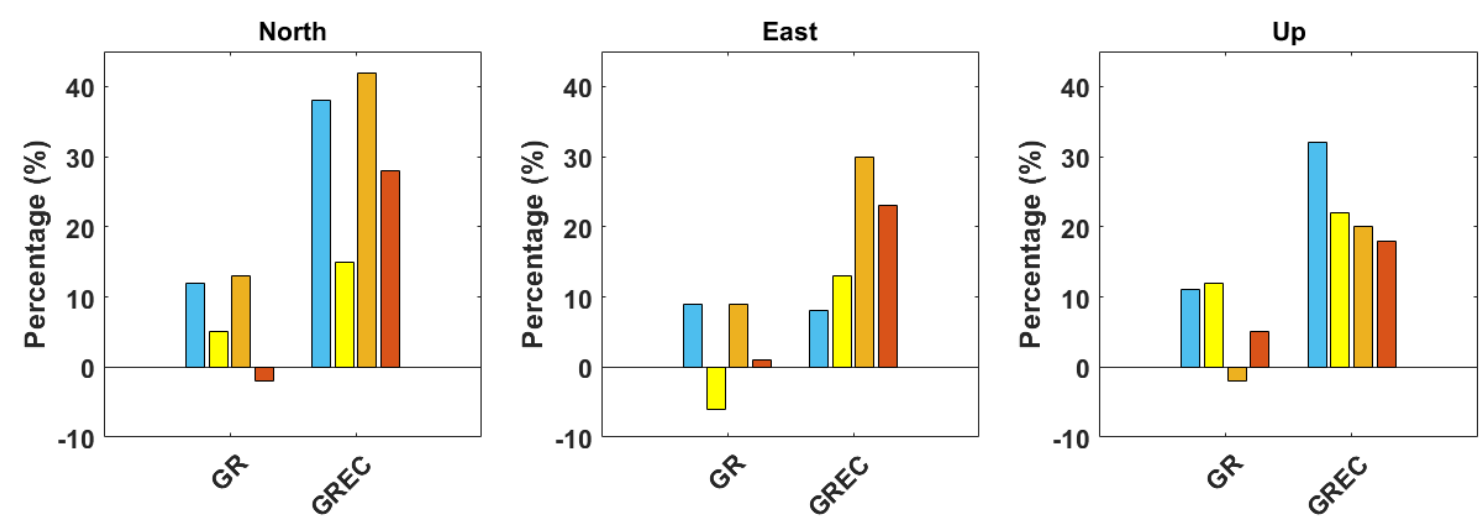

SITE-A $\square$ SITE-B $\square$ SITE-C $\square$ SITE-D

Figure 6. Repeatability improvements for $10^{\circ}$ cut-off angle option 

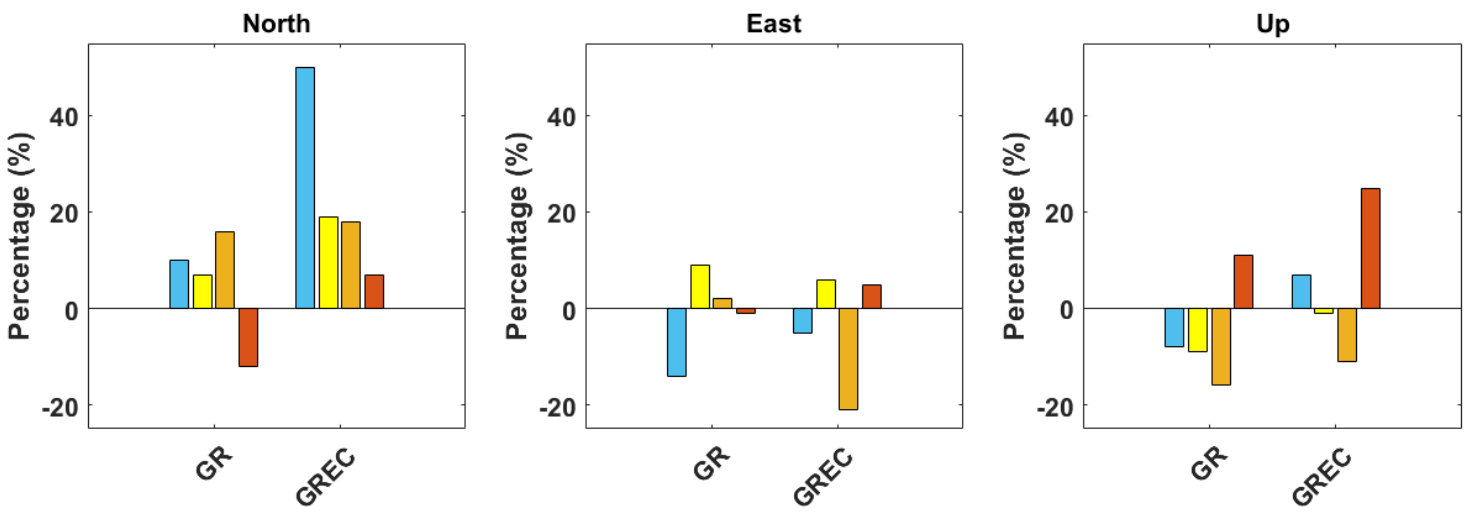

SITE-A $\square$ SITE-B $\square$ SITE-C $\square$ SITE-D

Figure 7. Repeatability improvements for $20^{\circ}$ cut-off angle option
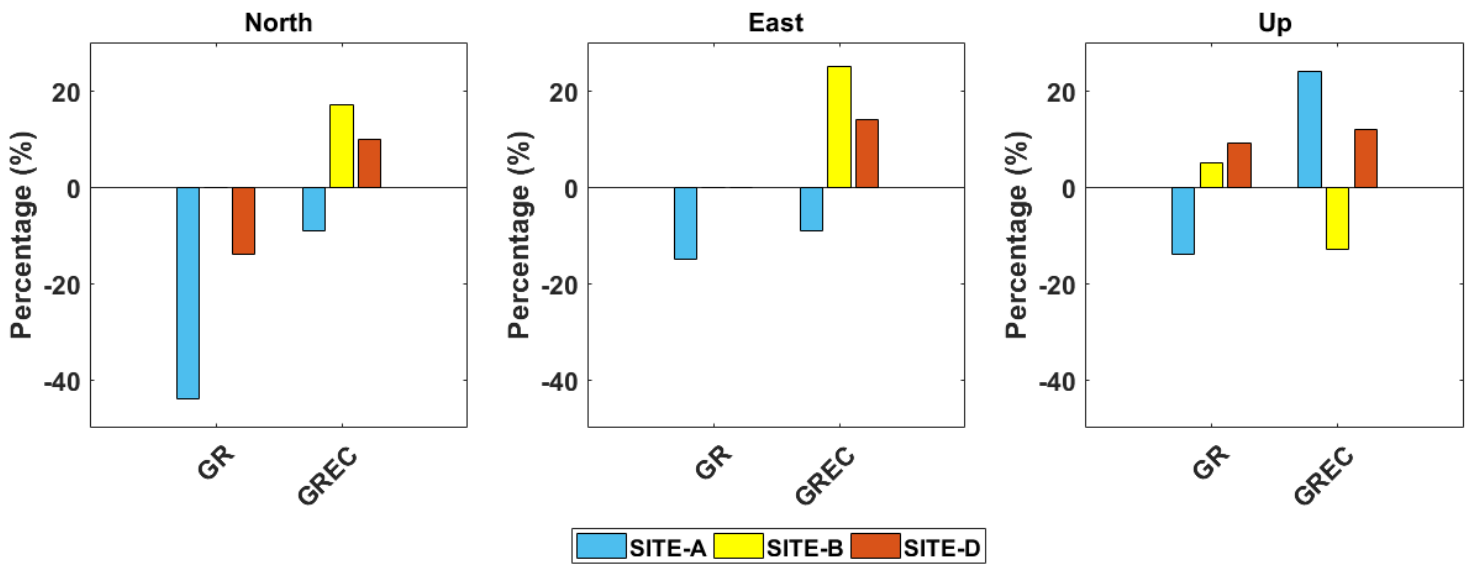

Figure 8. Repeatability improvements for $30^{\circ}$ cut-off angle option

As can be seen in Figure 6-8, GR and GREC configurations clearly improve the repeatability in the north, east and up components for $10^{\circ}$ cut-off angle option. Compared to GREC, the GR configuration has less effect in terms of std improvement. For $20^{\circ}$ cut-off angle option, GR and GREC improve the repeatability in the north component. While GREC has the least improvement at Site-D, GR has a negative value. Particularly in high cut-off angle options, multi-GNSS combinations have a negative effect. For the $30^{\circ}$ cut-off angle option, GR is bigger than $-40 \%$ in north component. However, some bars do not appear in Figure 8 because their values are equal to zero. Negative values may be due to the measurement time. Because the first phase lasted 5-hour, while the second and third phases only lasted 2 hours. Odijk and Wanninger (2017) investigated the combined GPS+BDS long RTK (80 km). Accordingly, the precision reaches $2 \mathrm{~cm}$ for the horizontal component and $5 \mathrm{~cm}$ for the vertical component in almost 3 hours. The results in this study are consistent with those in Odijk and Wanninger (2017). Also, since the G-30 session of Site-C was removed from the statistical analysis, it is not given in Figure 8.

Table 7. Mean values for G, GR and GREC sessions

\begin{tabular}{|c|c|c|c|c|c|c|c|c|c|c|}
\hline \multirow{2}{*}{ Sites } & \multirow{2}{*}{ Cut-off } & \multicolumn{3}{|c|}{ G } & \multicolumn{3}{|c|}{ GR } & \multicolumn{3}{|c|}{ GREC } \\
\hline & & $\mathrm{N}(\mathrm{cm})$ & $\mathrm{E}(\mathrm{cm})$ & $\mathrm{U}(\mathrm{cm})$ & $\mathrm{N}(\mathrm{cm})$ & $\mathrm{E}(\mathrm{cm})$ & $\mathrm{U}(\mathrm{cm})$ & $\mathrm{N}(\mathrm{cm})$ & $\mathrm{E}(\mathrm{cm})$ & $\mathrm{U}(\mathrm{cm})$ \\
\hline \multirow{3}{*}{ A } & $10^{\circ}$ & -0.62 & -0.17 & -0.72 & -0.49 & 0.04 & -2.13 & -0.86 & -0.02 & -2.02 \\
\hline & $20^{\circ}$ & -1.71 & -0.02 & 1.61 & -0.74 & -0.47 & -1.38 & -0.91 & -0.14 & -0.69 \\
\hline & $30^{\circ}$ & -0.47 & -0.84 & 0.59 & 0.11 & -0.99 & 0.19 & -0.63 & -0.86 & 1.33 \\
\hline \multirow{3}{*}{ B } & $10^{\circ}$ & 0.15 & -0.33 & -0.62 & -0.31 & -0.32 & -2.44 & -1.21 & 0.03 & -0.01 \\
\hline & $20^{\circ}$ & 0.32 & -1.49 & -1.71 & 0.45 & -1.19 & -3.40 & -0.32 & -0.90 & 0.48 \\
\hline & $30^{\circ}$ & -0.02 & -0.02 & -0.43 & -0.18 & 0.06 & -1.41 & -1.05 & 0.37 & -0.36 \\
\hline \multirow{3}{*}{$\mathrm{C}$} & $10^{\circ}$ & -0.73 & -0.45 & 4.00 & -0.72 & -0.50 & 2.25 & -1.35 & -0.61 & 3.38 \\
\hline & $20^{\circ}$ & -1.02 & 0.29 & 4.08 & -0.77 & -0.27 & 2.34 & -1.52 & -0.38 & 2.58 \\
\hline & $30^{\circ}$ & - & - & - & -1.20 & 1.08 & -1.64 & -0.58 & 0.29 & -0.63 \\
\hline \multirow{3}{*}{$\mathrm{D}$} & $10^{\circ}$ & -0.74 & -0.25 & -0.84 & -0.74 & -0.67 & -0.18 & 0.12 & -2.00 & 3.70 \\
\hline & $20^{\circ}$ & -0.34 & 0.06 & 1.43 & -0.74 & -0.29 & 1.60 & 0.49 & -2.46 & 3.76 \\
\hline & $30^{\circ}$ & -0.51 & -0.06 & 0.61 & -0.90 & -0.12 & 1.71 & 1.17 & -2.01 & 6.00 \\
\hline
\end{tabular}


In addition, mean values for each session were investigated (Table 7). Accordingly, the horizontal components vary between $-1.71 / 0.32 \mathrm{~cm},-1.20 / 1.08 \mathrm{~cm}$, and $-2.46 / 1.17 \mathrm{~cm}$ for G, GR, and GREC configurations, respectively. However, up components are in the range of $-1.71 / 4.08 \mathrm{~cm},-3.40 / 2.34 \mathrm{~cm}$, and $-2.02 / 6.00 \mathrm{~cm}$ for $\mathrm{G}$, $\mathrm{GR}$, and GREC configurations, respectively.

Furthermore, accuracy improvements were evaluated with the help of root mean square error (RMSe) values (Equation 3). The RMSe can be calculated as:

$$
R M S e=\sqrt{\frac{\sum(x)^{2}}{n}}
$$

where $x$ denotes the topocentric coordinate component and $n$ indicates the total number of measurements. RMSe values for each session was calculated using Equation 3. In Table 8, RMSe values for GPS-only solutions are given. As seen from Table 8, RMSe vary between $0.96 / 2.17 \mathrm{~cm}, 0.63 / 2.04 \mathrm{~cm}$, and $2.40 / 4.94$ $\mathrm{cm}$ for north, east, and up components, respectively.
Table 8. RMSe of GPS-only solutions

\begin{tabular}{ccccc}
\hline Sites & Cut-off & North (cm) & East $(\mathrm{cm})$ & Up (cm) \\
\hline \multirow{3}{*}{ A } & $10^{\circ}$ & 1.13 & 0.63 & 2.40 \\
& $20^{\circ}$ & 2.17 & 0.94 & 4.32 \\
& $30^{\circ}$ & 0.96 & 1.27 & 3.36 \\
\hline \multirow{3}{*}{ B } & $10^{\circ}$ & 1.02 & 1.13 & 2.54 \\
& $20^{\circ}$ & 1.33 & 2.04 & 3.66 \\
& $30^{\circ}$ & 1.13 & 1.10 & 3.85 \\
\hline \multirow{3}{*}{ C } & $10^{\circ}$ & 1.66 & 1.09 & 4.69 \\
& $20^{\circ}$ & 2.16 & 1.10 & 4.94 \\
& $30^{\circ}$ & - & - & - \\
\hline \multirow{2}{*}{$\mathrm{D}$} & $10^{\circ}$ & 1.59 & 0.97 & 2.74 \\
& $20^{\circ}$ & 1.29 & 1.23 & 3.91 \\
& $30^{\circ}$ & 1.11 & 0.89 & 2.73 \\
\hline
\end{tabular}

A simple equation such as Equation 2 was used to assess the RMSe values as improvements. In Figures 911, accuracy improvements are given for each test site and elevation cut-off angle option.
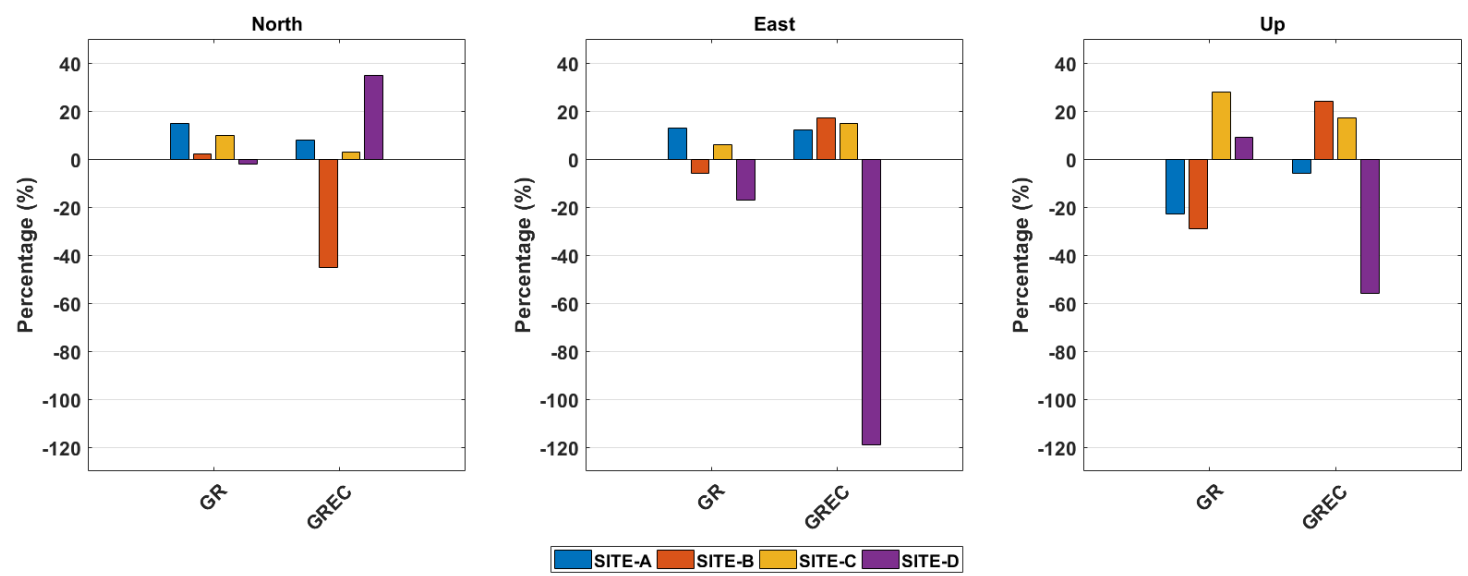

Figure 9. Accuracy improvements for $10^{\circ}$ cut-off angle option
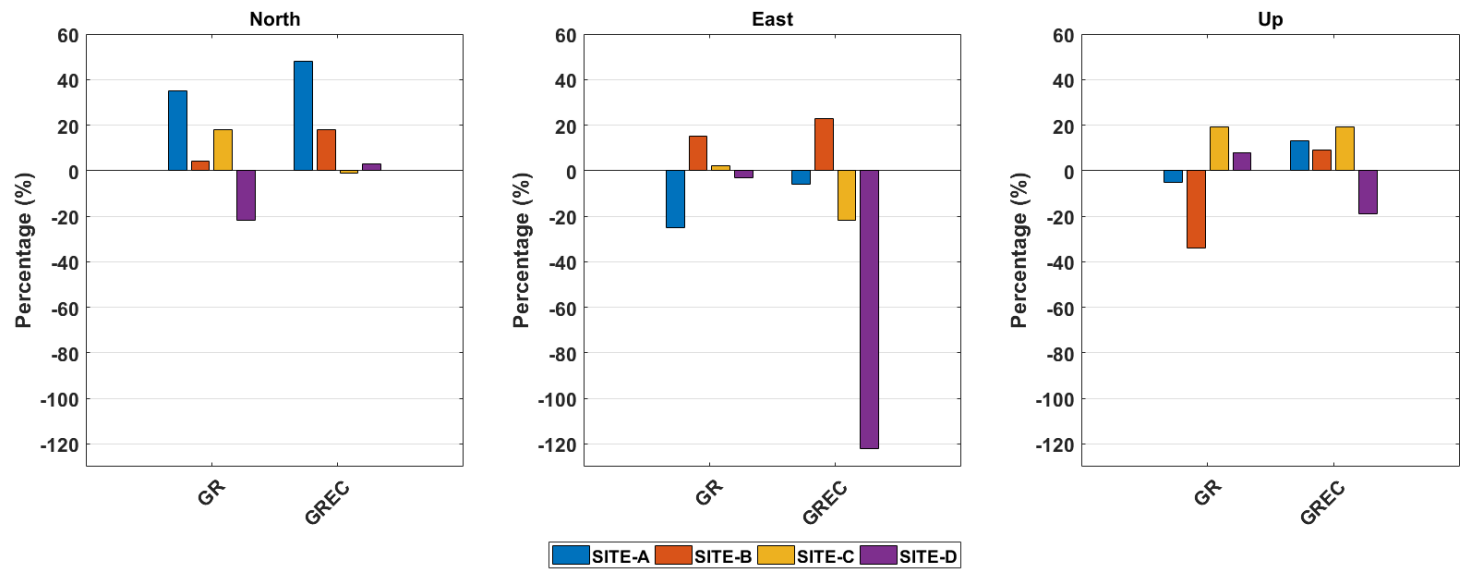

Figure 10. Accuracy improvements for $20^{\circ}$ cut-off angle option 

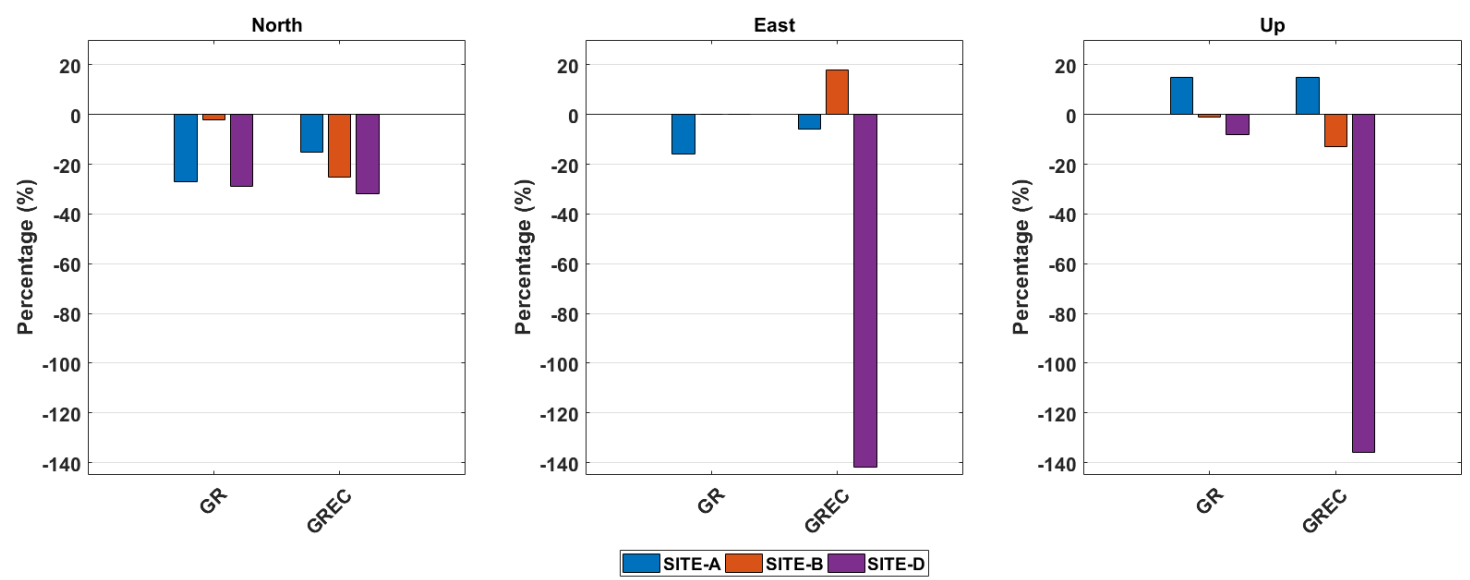

Figure 11. Accuracy improvements for $30^{\circ}$ cut-off angle option

Both GR and GREC have improved the accuracy in Site-A at the low elevation cut-off angle. For Site-A, multiGNSS were not increase at higher cut-off angles. For SiteC, multi-GNSS improved the accuracy. In general, GR and GREC degraded the accuracies at Site-D. The maximum improvement in the horizontal component is in the north component of Site-A.

The error distribution for each session and coordinate component were investigated for better
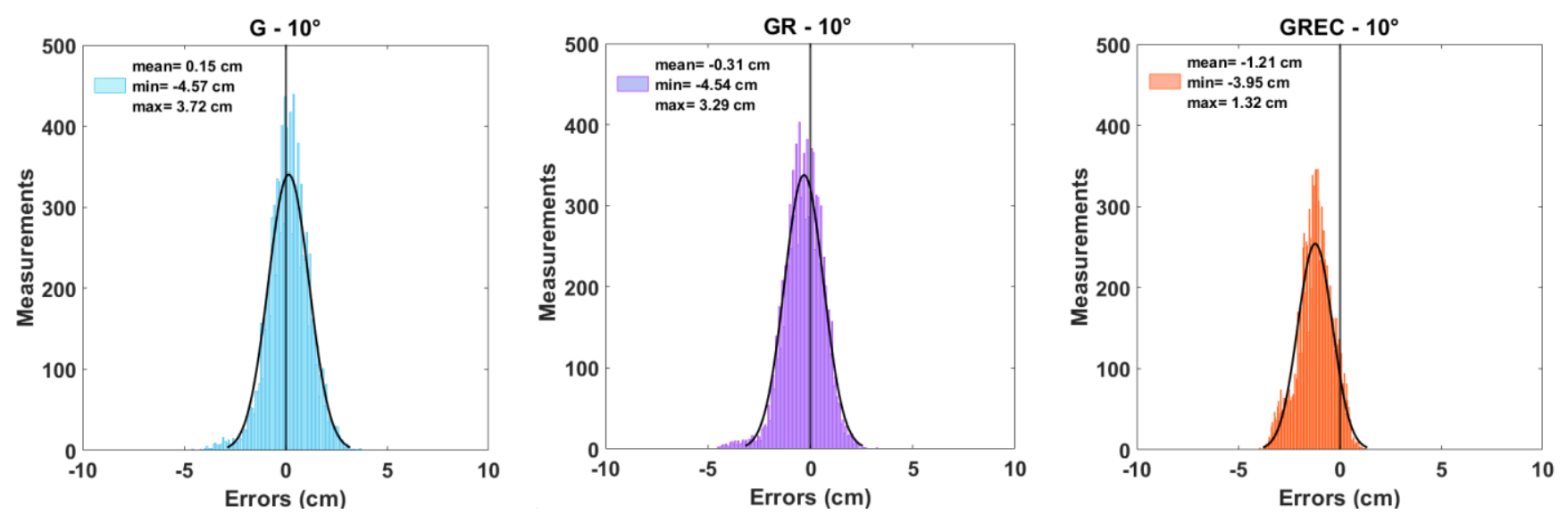

Figure 12. Error distribution of the north component for G, GR and GREC configurations (Site-B)

As seen in Figure 13-14, the error distributions for horizontal components are in the range of $-5.0 / 4.0 \mathrm{~cm}$. Whereas in the vertical component, errors can reach -10 $\mathrm{cm}$ (Figure 14). Moreover, it can be stated that the errors in all components are similar to the Gaussian distribution. For the north component, GPS-only solutions are better than multi-GNSS solutions. The solution of GREC is biased with a mean of $-1.20 \mathrm{~cm}$ in the north component. Whereas GPS-only and GR solutions are similar, GREC provides the ideal solution in east and up components. For the up component, the solution of GR is biased with a mean of $-2.44 \mathrm{~cm}$. As a result, GR improved repeatability, but not accuracy since the solution is biased. The biased error distributions like this degrade the positioning accuracy. Therefore, multiple GNSS combinations do not always improve accuracy as can be seen from their error distributions (Figure 12).

For a more in-depth analysis, the atmospheric conditions were examined as they are crucial to real-time positioning. Mainly, the atmospheric effects in comprehension of data. The error is defined as the RTK coordinate differences from the assumed real value obtained from the static processing. In order to represent error distribution, topocentric coordinates (north, east, and up) were used. For the sake of simplicity, only data belong to the first phase of Site-B is presented in this manuscript (Figure 12-14). positioning with GNSS are examined by means of ionosphere and troposphere. GNSS signals are exposed to free electrons in the ionosphere layer of the atmosphere that disrupts the signal propagation. The density of electron content in the ionosphere is described as Total Electron Content (TEC). The major changes in TEC value indicate the ionospheric disturbance. Moreover, space weather condition indices can provide information about anomalies in the ionosphere. When there is an ionospheric storm, the indices exceed their limit values (Bothmer and Daglis 2007; Alcay and Gungor 2020). Therefore, in this study, geomagnetic storm (Kp), geomagnetic activity (Dst), and solar activity (F10.7) indices examined to check whether any ionospheric disturbance during the field tests (Figure 15). As a result, Kp, Dst, and F10.7 index values do not exceed limit values. Therefore, there is no ionospheric storm during field tests. 

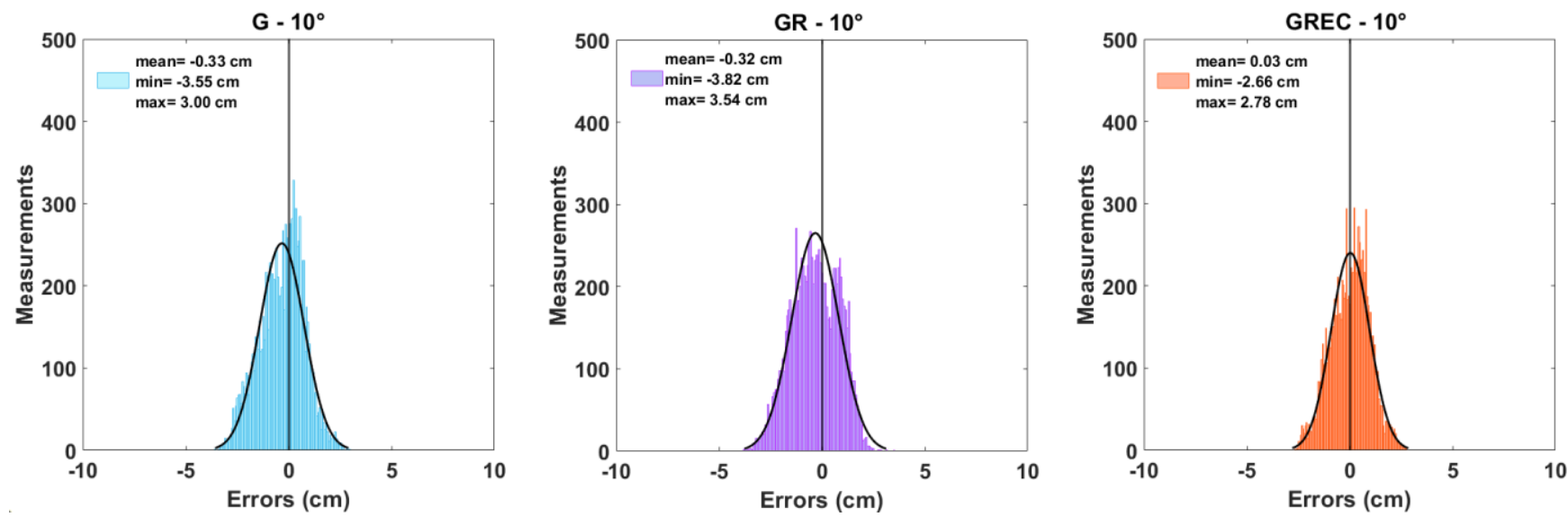

Figure 13. Error distribution of the east component for G, GR and GREC configurations (Site-B)
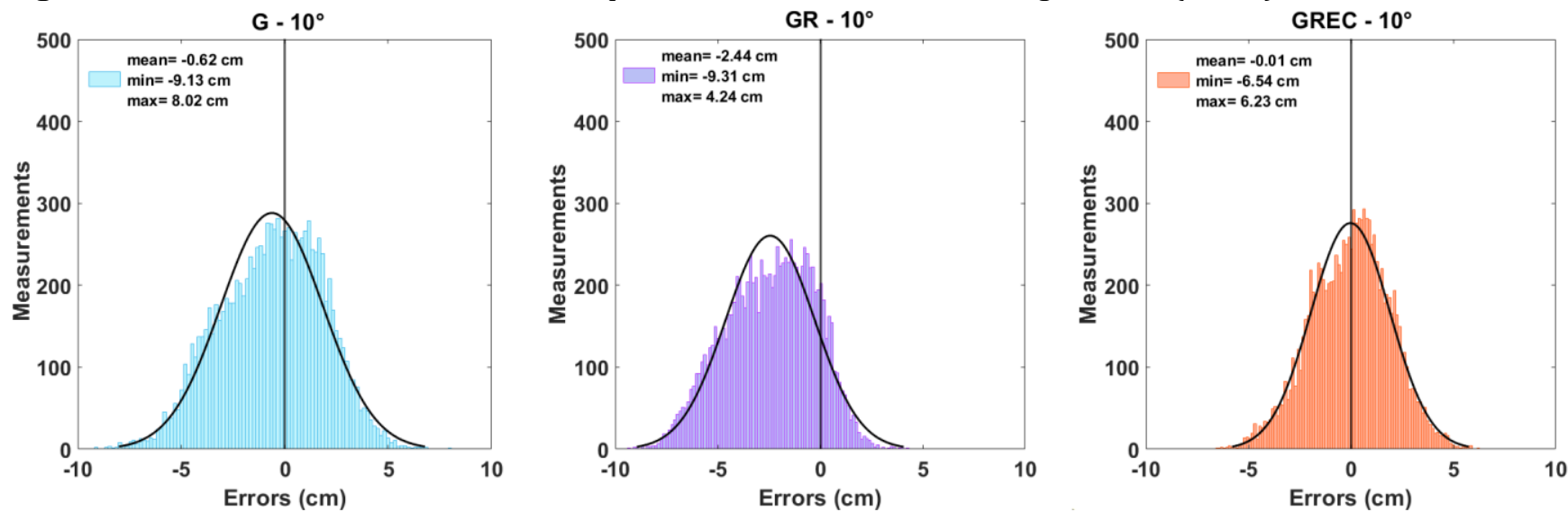

Figure 14. Error distribution of the up component for G, GR and GREC configurations (Site-B)
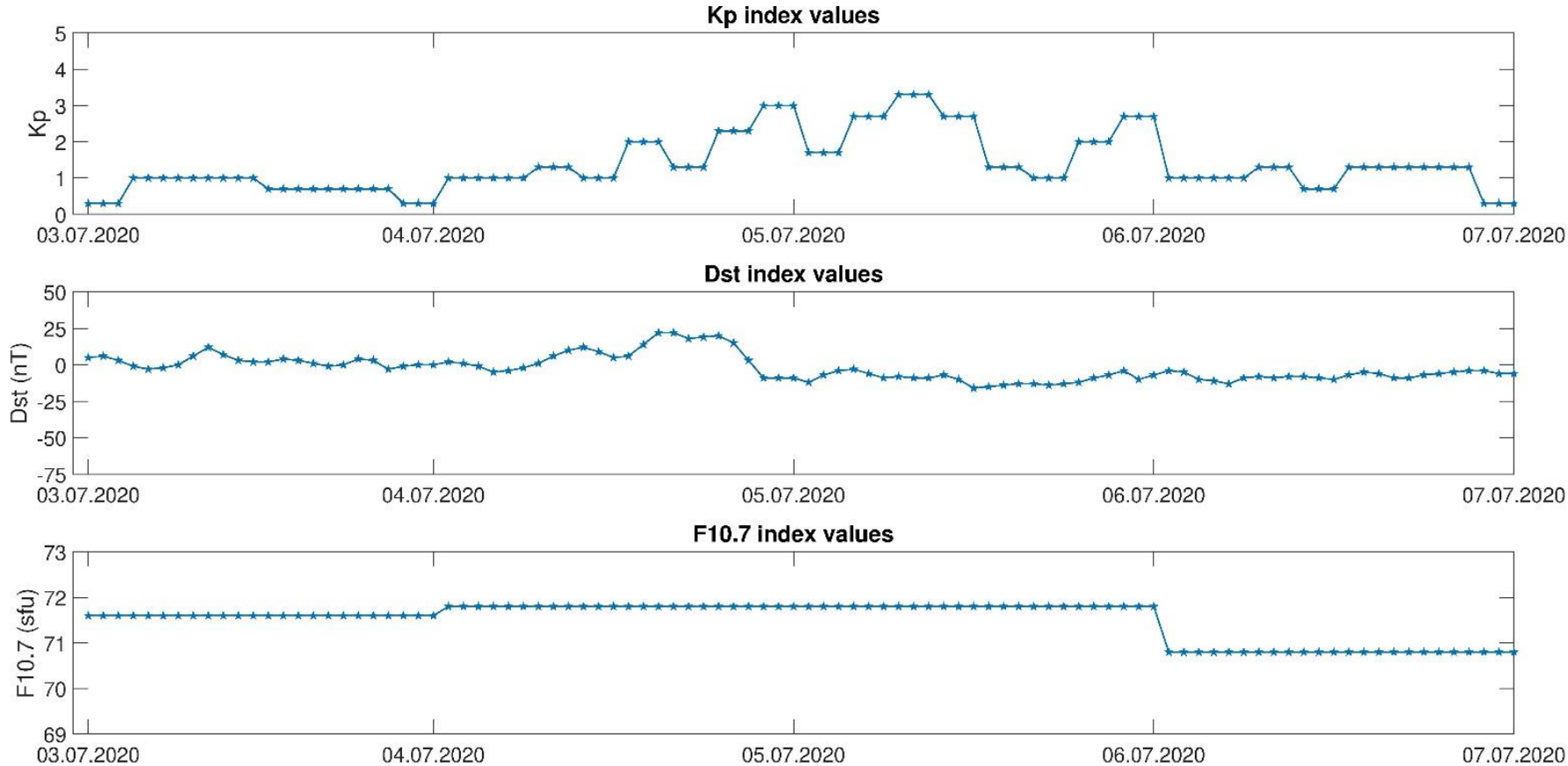

Figure 15. Kp, Dst and F10.7 index values during the field tests (https://omniweb.gsfc.nasa.gov/form/dx1.html) 

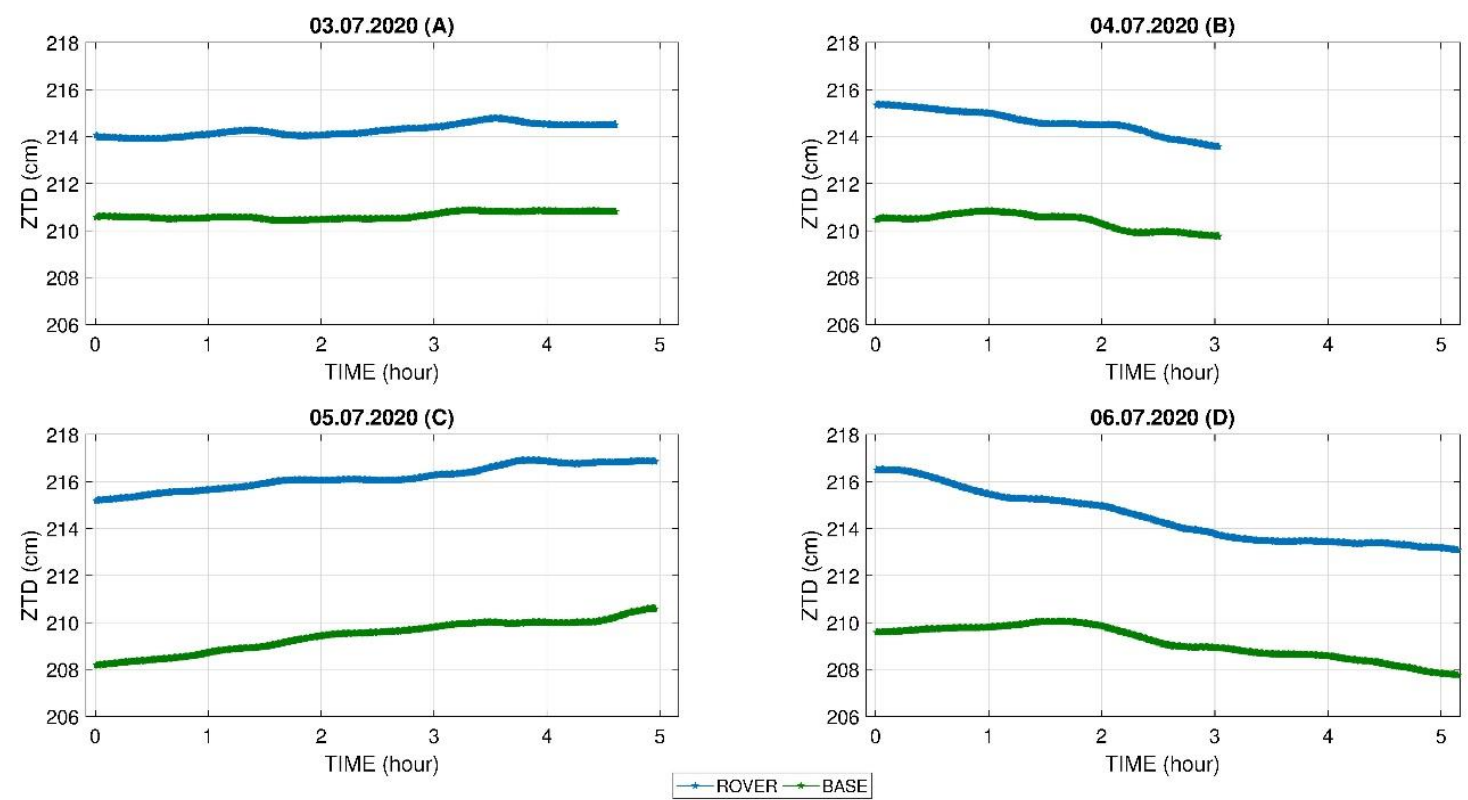

Figure 16. ZTD values at the first phase of measurements (https://webapp.geod.nrcan.gc.ca/geod/tools-outils/ppp.php)

Another subject related to GNSS signal path delay is the nonionized layer of the atmosphere so-called, troposphere. The tropospheric delay consists of hydrostatic and wet components. With the PPP method, coordinate components, ambiguities, receiver clock error, and tropospheric delay parameters are estimated (Hofmann-Wellenhof et al. 2007). For this study, tropospheric delays were obtained by using CSRS-PPP (The Canadian Spatial Reference System-PPP) online service. CSRS-PPP is a practical and robust online PPP post-processing service for estimating coordinate or troposphere (Mendez Astudillo et al. 2018). The CSRSPPP provides tropospheric dry and wet components separately. The sum of dry and wet components is equal to ZTD (Zenith Total Delay). Since the static data recording was only performed in the first phase of measurements, only ZTD values in the first phase could be evaluated. As the troposphere condition was the same for different satellite configurations at the test sites, only data of GR was processed since the CSRS-PPP supports GPS and GLONASS satellite systems. Besides, the data of the base station was processed to distinguish the troposphere correlation between the base station and the rover. Figure 16 shows the ZTD values of base station and rovers for each measurement day. Also, the ZTD differences between base station and rover were examined. Accordingly, the maximum ZTD differences are computed as $3.97 \mathrm{~cm}, 4.88 \mathrm{~cm}, 7.07 \mathrm{~cm}$, and $6.92 \mathrm{~cm}$ for the consecutive days (3-6 July 2020), respectively. These differences should be taken into consideration since they can defect the solutions. Moreover, the ZTD correlation coefficients between the base station and rovers were computed and given in Table 9 .

Table 9. The ZTD correlation percentages

\begin{tabular}{ccc}
\hline Sites & Date & Correlation $(\%)$ \\
\hline A & 03.07 .2020 & 84.93 \\
B & 04.07 .2020 & 81.20 \\
C & 05.07 .2020 & 95.37 \\
D & 06.07 .2020 & 87.15
\end{tabular}

As clearly seen from Table 9, troposphere highly correlated between the base station and rovers in all four sites. Furthermore, to better illustrate the high correlation, the RTK coordinate time series of G, GR and GREC configurations at $10^{\circ}$ cut-off angle option is provided in Figure 17, as an example (Site-D). As can be seen from the up component in Figure 17, the G and GREC solutions show a similar trend with the ZTD difference.
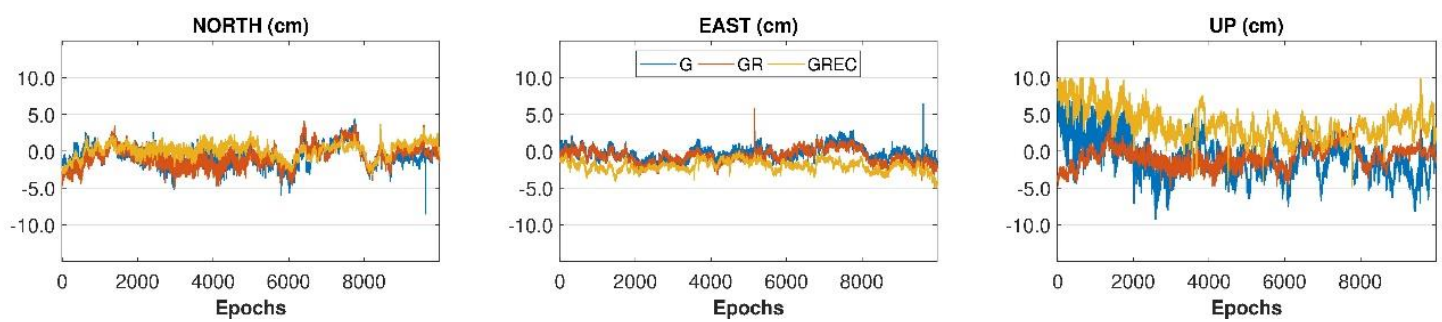

Figure 17. The coordinate time series for the day 06.07.2020 (Site-D)

\section{CONCLUSION}

In this study, the performance of the RTK method with different satellite combinations (G, GR and GREC) has been investigated comprehensively. For this purpose, a field test was conducted considering short and long-baseline lengths. Moreover, low and high satellite elevation cut-off angles were used to represent urban canyon and open sky conditions. The ground truth coordinates of rovers were obtained by post-process 
relative method using the same base station as the reference. The results were evaluated considering atmospheric conditions, which is important for real time positioning.

When the results are analyzed, multi-GNSS combinations have an undeniable impact on repeatability. In terms of accuracy, the maximum RMSe of GPS-only solutions were $2.17 \mathrm{~cm}, 2.04$ and 4.94 for north, east and up components, respectively. It can be concluded that single-base RTK can provide a few centimeters level of accuracy even for baseline distances up to $\sim 80 \mathrm{~km}$. Despite the fact that the number of satellites increases the RTK performance, in this study, the multi-GNSS combinations are not always improved the results. Even at high cut-off angle, GPS-only solutions are more accurate than at a very high cut-off angle. It can be concluded that, when the satellite geometry is good, GPS-only solutions are comparable with multi-GNSS solutions. However, baseline distance is an important issue for RTK measurements. From the results of this case study, it can be stated that the horizontal accuracy differences between short and long-baseline distances are sub-centimeter level. As well, the vertical accuracy differences are in a few centimeters level.

The changes in the troposphere and ionosphere layers were investigated in terms of atmospheric conditions. There was not any ionospheric storm during applications. When the troposphere is evaluated, in general, it is found that ZTD values are correlated between base station and rover. However, the maximum ZTD differences of the base-rover station achieve 7.07 $\mathrm{cm}$. As the height difference increased the maximum ZTD difference is increased. Due to this reason, as well as the baseline distance, the height difference should be considered for a better comparison of multi-GNSS RTK measurements.

\section{ACKNOWLEDMENT}

This study was funded by Necmettin Erbakan University Scientific Research Projects (Project No: 201319004). We appreciate the technical team of CHC Turkey and Ufuk R. Ozbey for their support during this study. The authors also thank MIT for providing GAMIT/GLOBK software.

\section{Author contribution}

Omer Faruk Atiz: Methodology, Visualization, Editing; Ceren Konukseven: Methodology, Writing-Original draft preparation, Editing; Salih Sermet Ögü̈tcü: Conceptualization, Writing-Original draft preparation; Salih Alçay: Conceptualization, Investigation, WritingReviewing

\section{Conflicts of interest}

The authors declare no conflicts of interest.

\section{REFERENCES}

Alçay S \& Atiz Ö (2021). Farklı Yazılımlar Kullanılarak Gerçek Zamanlı Hassas Nokta Konum Belirleme (RT-
PPP) Yönteminin Performansının İncelenmesi. Geomatik, $\quad 6 \quad$ (1), 77-83. https://doi.org/10.29128/geomatik.687709.

Alcay S \& Gungor M (2020). Investigation of ionospheric TEC anomalies caused by space weather conditions. Astrophysics and Space Science, 365(9), 1-15. https://doi.org/10.1007/s10509-020-03862-x.

Atiz 0, Alcay S, Ogutcu S \& Kalayci I (2020). Necmettin Erbakan University Continuously Operating Reference Station. Intercontinental Geoinformation Days (IGD), 44-47, Mersin, Turkey.

Baybura T, Tiryakioğlu İ, Uğur M A, Solak H İ \& Şafak Ş (2019). Examining the accuracy of network RTK and long base RTK methods with repetitive measurements. Journal of Sensors, 2019. https://doi.org/10.1155/2019/3572605.

Bothmer V \& Daglis I A (2007). Space weather: physics and effects. Springer Science \& Business Media. ISBN 978-3-540-23907-9

Bramanto B, Gumilar I, Taufik M \& Hermawan I M D (2019). Long-range Single Baseline RTK GNSS Positioning for Land Cadastral Survey Mapping. In E3S Web of Conferences (ISGNSS 2018), 94, 01022, Bali, Indonesia.

Castro-Arvizu J M, Medina D \& Ziebold R (2020). Impact of Satellite Elevation Mask in GPS+ Galileo RTK Positioning. In Institute of Navigation International Technical Meeting 2020, 487-498, San Diego, California.

Dabove P \& Di Pietra V (2019). Single-baseline RTK positioning using dual-frequency GNSS receivers inside smartphones. Sensors, 19(19), 4302. http://dx.doi.org/10.3390/s19194302.

Dabove P (2019). The usability of GNSS mass-market receivers for cadastral surveys considering RTK and NRTK techniques. Geodesy and Geodynamics, 10(4), 282-289. https://doi.org/10.1016/j.geog.2019.04.006.

Edwards S J, Clarke P J, Penna N T \& Goebell S (2010). An examination of network RTK GPS services in Great Britain. Survey Review, 42(316), 107-121. https://doi.org/10.1179/003962610X12572516251 529.

El-Mowafy A \& Kubo N (2017). Integrity monitoring of vehicle positioning in urban environment using RTKGNSS, IMU and speedometer. Measurement Science and Technology, 28(5), 055102. https://doi.org/10.1088/1361-6501/aa5c66.

Erenoglu R C (2017). A comprehensive evaluation of GNSS-and CORS-based positioning and terrestrial surveying for cadastral surveys. Survey Review, 49(352), 28-38. https://doi.org/10.1080/00396265.2015.1104093.

Herring T A, King R W \& McClusky S C (2010). Introduction to GAMIT/GLOBK. Massachusetts Institute of Technology, Cambridge, Massachusetts.

Hofmann-Wellenhof B, Lichtenegger H \& Wasle E (2007). GNSS-global navigation satellite systems: GPS, GLONASS, Galileo, and more. Springer Science \& Business Media. ISBN 978-3-211-73012-6

Kim D \& Langley R B (2008). Improving Long-Range RTK. GPS World. 
Kouba J \& Héroux P (2001). Precise point positioning using IGS orbit and clock products. GPS solutions, 5(2), 12-28. https://doi.org/10.1007/PL00012883.

Lagler K, Schindelegger M, Böhm J, Krásná H \& Nilsson T (2013). GPT2: Empirical slant delay model for radio space geodetic techniques. Geophysical research letters, $\quad 40(6)$, 1069-1073. https://doi.org/10.1002/grl.50288.

Li G, Wu J, Zhao C \& Tian Y (2017b). Double differencing within GNSS constellations. GPS Solutions, 21(3), 1161-1177. https://doi.org/10.1007/s10291-0170599-4.

Li T, Zhang H, Niu X \& Gao Z (2017a). Tightly-coupled integration of multi-GNSS single-frequency RTK and MEMS-IMU for enhanced positioning performance. Sensors, $17(11)$, 2462. http://dx.doi.org/10.3390/s17112462.

Li X, Lv H, Ma F, Li X, Liu J \& Jiang Z (2019). GNSS RTK positioning augmented with large LEO constellation. $\begin{array}{lll}\text { Remote } \quad \text { Sensing, } & 11(3),\end{array}$ https://doi.org/10.3390/rs11030228.

Luo X, Schaufler S, Branzanti M \& Chen J (2020). Assessing the benefits of Galileo to high-precision GNSS positioning-RTK, PPP and post-processing. Advances in Space Research. https://doi.org/10.1016/j.asr.2020.08.022.

Mendez Astudillo J, Lau L, Tang Y T \& Moore T (2018). Analysing the zenith tropospheric delay estimates in on-line precise point positioning (PPP) services and PPP software packages. Sensors, 18(2), 580. https://doi.org/10.3390/s18020580.

Mi X, Zhang B \& Yuan Y (2019). Multi-GNSS inter-system biases: estimability analysis and impact on RTK positioning. GPS Solutions, 23(3), 81. https://doi.org/10.1007/s10291-019-0873-8.

Odijk D \& Teunissen P J (2013). Characterization of between-receiver GPS-Galileo inter-system biases and their effect on mixed ambiguity resolution. GPS solutions. $17(4), \quad 521-533$ https://doi.org/10.1007/s10291-012-0298-0.

Odijk D \& Wanninger L (2017). Differential Positioning. In: Teunissen P.J., Montenbruck O. (eds) Springer Handbook of Global Navigation Satellite Systems. Springer Handbooks. ISBN 978-3-319-42928-1

Odijk D, Verhagen S \& Teunissen P J G (2012). Mediumdistance GPS ambiguity resolution with controlled failure rate. In Geodesy for Planet Earth (pp. 745751). Springer, Berlin, Heidelberg. https://doi.org/10.1007/978-3-642-20338-1_93.

Odolinski R, Teunissen P J G \& Odijk D (2015a). Combined GPS+ BDS for short to long baseline RTK positioning. Measurement Science and Technology, 26(4), 045801. http://dx.doi.org/10.1088/09570233/26/4/045801.

Odolinski R, Teunissen P J G \& Odijk D (2015b). Combined BDS, Galileo, QZSS and GPS Single-
Frequency RTK. GPS Solutions, 19(1), 151-163. https://doi.org/10.1007/s10291-014-0376-6.

Ogutcu S \& Kalayci I (2018). Accuracy and precision of network-based RTK techniques as a function of baseline distance and occupation time. Arabian Journal of Geosciences, 11(13), 354. https://doi.org/10.1007/s12517-018-3712-2.

Ogutcu S (2019). Temporal correlation length of network based RTK techniques. Measurement, 134, 539-547. https://doi.org/10.1016/j.measurement.2018.10.09 9.

Paziewski J \& Wielgosz P (2017). Investigation of some selected strategies for multi-GNSS instantaneous RTK positioning. Advances in Space Research, 59(1), 1223. https://doi.org/10.1016/j.asr.2016.08.034.

Shu B, Liu H, Xu L, Qian C, Gong X \& An X (2018). Performance analysis of BDS medium-long baseline RTK positioning using an empirical troposphere model. Sensors, 18(4), 1199. https://doi.org/10.3390/s18041199.

Tian Y, Sui L, Xiao G, Zhao D \& Tian Y (2019). Analysis of Galileo/BDS/GPS signals and RTK performance. GPS Solutions, $23(2), \quad 37$. https://doi.org/10.1007/s10291-019-0831-5.

Weber G, Dettmering D \& Gebhard H (2005). Networked transport of RTCM via internet protocol (NTRIP). In A Window on the Future of Geodesy, 60-64, Berlin, Germany.

Wessel P, Luis J F, Uieda L, Scharroo R, Wobbe F, Smith W H F \& Tian D (2019). The generic mapping tools version 6. Geochemistry, Geophysics, Geosystems, 20(11), https://doi.org/10.1029/2019GC008515.

Wielgosz P, Kashani I \& Grejner-Brzezinska D (2005). Analysis of long-range network RTK during a severe ionospheric storm. Journal of Geodesy, 79(9), 524531. https://doi.org/10.1007/s00190-005-0003-y.

Yu J, Yan B, Meng X, Shao X \& Ye H (2016). Measurement of bridge dynamic responses using network-based real-time kinematic GNSS technique. Journal of Surveying Engineering, 142(3), 04015013. http://dx.doi.org/10.1061/(ASCE)SU.19435428.0000167.

Zhang Y, Kubo N, Chen J, Chu F Y, Wang H \& Wang J (2020). Contribution of QZSS with four satellites to multi-GNSS long baseline RTK. Journal of Spatial Science, 65(1), 41-60. https://doi.org/10.1080/14498596.2019.1646676.

Zumberge J F, Heflin M B, Jefferson D C, Watkins M M \& Webb F H (1997). Precise point positioning for the efficient and robust analysis of GPS data from large networks. Journal of geophysical research: solid earth, 102(B3), 5005-5017. https://doi.org/10.1029/96JB03860. 